Original Research Paper

\title{
A Study to Assess the Knowledge Regarding Role of Teachers in Promoting Healthy Behavior in School Children Among Primary School Teachers in Selected Primary Schools, Hyderabad, Telangana
}

\author{
Valluri Lucy Kezia Kamala Kumari \\ Nursing -Community Health Nursing, Vinayaka Mission's College of Nursing, Karaikal, India
}

\begin{abstract}
Article history
Received: 23-07-2021

Revised: 08-09-2021

Accepted: 23-09-2021
\end{abstract}

Email: kezia_kumari2006@yahoo.com

\begin{abstract}
Behavioral problems may affect the children education and they cannot good in a subject after trying hard. Teacher are the second parents to teach the children to develop a good life with good behavior this helps in getting good academic results and becomes a good citizen of the country. Every teacher should have the knowledge in promoting healthy behavior in school children it includes conduct, scholastic and emotional behavior. The researcher wants to assess the knowledge of the school teachers in promoting healthy behavior in school children during their educational period and improve the knowledge of school teachers by providing pamphlets regarding role of teacher in promoting healthy behavior in school children. The lack of knowledge in school teachers may lead to many problems in school children lives. The objectives of the study were 1. To Assess the knowledge of teachers regarding role of teachers in Promoting Healthy Behavior in School Children. 2. To find out the association between the knowledge scores of school teachers regarding role of teachers in promoting healthy behavior in school children with selected demographic Variables.3. To provide a pamphlet regarding role of Teachers in Promoting Healthy Behavior in School Children. The data collection procedure was carried out with the structured questionnaire and the samples were taken from in Selected Private Primary Schools, Almasguda, Hyderabad, Telangana. Sample of 60 primary school teachers were taken. Variables are Age, Sex, Religion, Education, Income. Marital status, years of experience, attended training programmer on behavioral problems of school children. Majority of the subjects $60 \%$ were in the age group above 40 years, $65 \%$ were females, $76.7 \%$ were Hindus, $70 \%$ of subjects were done graduation with B.Ed., $60 \%$ were in the income group of Rs. 15,000 t0 20,000,90\% were married, $65 \%$ were 05 years' experience, none of the teachers were attended training programmer on behavioral problems of school children.
\end{abstract}

Keywords: Knowledge, Primary, School Teachers, Promoting, Healthy Behavior, School Children

\section{Introduction}

In school age every child requires a proper guidance by their teachers. Teacher should pay attention on both academic and behavior of the children in the class room. Every teacher should have awareness of importance of healthy behavior. The teachers who are having knowledge how to treat the children at class room. Teachers' knowledge and positive attitude may help to prevent the behavioral problems in students at school level (Bhatia et al., 2000).

Many of the schoolchildren are suffering from various behavioral problems without proper guidance by the teachers at school level School going children are spending most of the time in school so, the school teachers have to play a major 
role in developing healthy behavior in school children. School Children are influenced by their teacher's behavior. It is necessary to conduct health educational programmers on prevention of behavior problems in school children. Disruptive behavior of children shows bad effects on the children life, society and also on the country (Achenbach et al., 2008).

India State-Level Disease Burden Initiative Mental Disorders Collaborators 2020, in children's mental disorders are the most common causes of morbidities in India. These disorders were present 197.3 million $(95 \%$ UI $178 \cdot 5-216 \cdot 4)$ people, comprising $14.3 \%$ of the total population of India in 2017 (Sagar et al., 2020).

According to Malhotra and Patra, 2014 the prevalence rate of psychiatric disorders among children and adolescents in India were reported to be $6.46 \%$ in the community and $23.33 \%$ in the schools (Malhotra and Patra, 2014).

According to WHO September 2020 Childhood behavioral problems are the second leading cause of disease burden in young adolescents aged 10-14 years and the eleventh leading cause among older adolescents aged 15-19 years (Sunitha and Gururaj, 2014).

Childhood behavioral problems include lying, stealing, aggression, attention deficit hyperactivity disorder (characterized by difficulty paying attention, excessive activity and acting without regards to consequences, which are otherwise not appropriate for a person's age), learning disorder, anxiety, depression and nail biting. Childhood behavioral problems can effect on their life and may result in disruptive behavior (Dutta, 2014).

According to centers for disease control and prevention $7.4 \%$ of children aged 3-17 years (approximately4.5 million) have a diagnosed with behavior problem in United States children (APA, 2013).

Every teacher should educate the school children to understand and follow the rules and regulations of the society. Healthy behavior of the school children good behavior is a good asset to them to the family and society. Teachers have to motivate the school children to follow the healthy behavior and encourage them to reach their goals (Rajanidevi, 2019).

\section{Materials and Methods}

Research Approach: Quantitative approach.

Research Design: Non experimental design.

Setting of the study: The study was conducted at Private Primary schools at Almasguda, Rural area, Hyderabad, Telangana.

Population: Primary school teachers dealing $\mathrm{I}^{\text {st }}$ to $5^{\text {th }}$ class, who are working in rural area Private primary schools were the population of the study.

\section{Sample and Sampling Techniques}

Sample size: 60

Sampling technique: Convenient sample.

Development of Tool: Based on the objectives, a structural questionnaire was prepared to assess the knowledge of school teachers regarding Role of Teachers in Promoting Healthy Behavior in School Children among Primary School Teachers. Developed and validated a pamphlet regarding Role of Teachers in Promoting Healthy Behavior in School Children to distribute to the teachers.

\section{Results}

The data was analyzed using descriptive and inferential statistics.

The study results showed that $10.0 \%$ of the teachers were had inadequate knowledge, $85.0 \%$ of them were had moderate knowledge and $5 \%$ of them had adequate knowledge regarding role of Teachers in Promoting Healthy Behavior in School Children. There is significant association between level of knowledge of teachers with selected demographic variables like age, education and year of experience Fig. 1.

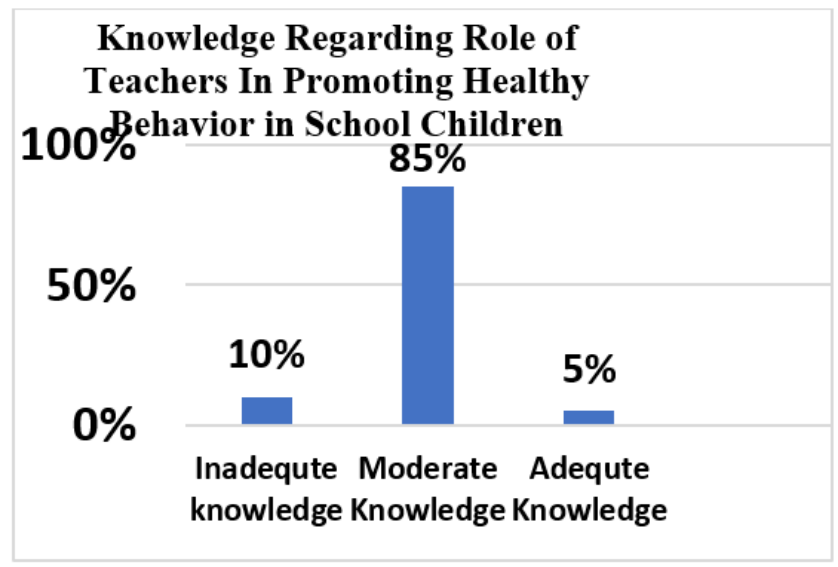

Fig. 1: Knowledge level of school teachers regarding promoting healthy behavior in school children 


\section{Discussion}

This study attempted to assess the Knowledge of teachers regarding role of Teachers in Promoting Healthy Behavior in School Children. The major findings of the study were description of baseline variables of teachers was majority of the teachers $60 \%$ were in the age group above 40 years, $65 \%$ were females, $76.7 \%$ were Hindus, $70 \%$ of subjects were done graduation with B.Ed., $60 \%$ were in the income group of Rs. 15,000 to 20,000 , $90 \%$ were married, $65 \%$ were 0-5years' experience and the teachers were attended training programmer on behavioral problems of school children were none.

The First Objective of the Study to assess the level of knowledge regarding role of teachers in Promoting Healthy Behavior in School Children. This study revealed $10.0 \%$ of the teachers had inadequate knowledge, $85.0 \%$ of them had moderate knowledge and $5 \%$ of them had adequate knowledge regarding role of school Teachers in Promoting Healthy Behavior in School Children.

The second Objective of the Study was to find out the association between knowledge scores of school teachers regarding role of teachers in promoting healthy behavior in school children with selected demographic Variables. There is significant association between the level of knowledge of teachers with selected demographic variables like age, education and year of experience.

The third objective of the study was to provide a pamphlet regarding role of teachers in Promoting Healthy Behavior in School Children. Prepared a pamphlet on role of teachers in Promoting Healthy Behavior in School Children and distributed to all the school teachers.

Vijayan et al. (2016) has shown in results that teacher has strong purposeful beliefs, high expectations, a positive friendly manner and an enthusiastic and engaging approach to teaching and learning then the classroom will be set up for students to succeed whatever the situation or place. Similarly, researcher feels that using self-monitoring techniques and specific strategies helps for healthy behavior in school children (Vijayan et al., 2016).

\section{Conclusion}

Every teacher has to follow the above some of the basic and important steps to promote healthy behavior in school children. In school age only we can guide and educate the children about importance of healthy behavior. The study findings were revealed that majority $(85 \%)$ of the teachers had moderate adequate knowledge. There is significant association between the level of knowledge of teachers with selected demographic variables like age, education and year of experience. This study result shows that the teachers are requires training programmers on promoting healthy behavior in school children. Development of training modules, life skill training so that they can take an active role at school level to be included in curriculum.
Significance of this study and findings was redound to the benefit of society considering that teachers to play an important role in developing and promoting healthy behavior in school children. Children with behavioral problems may face problems like lying, stealing and aggression effect on their life and chances to become criminal, ADHD and learning problems may effect on their studies anxiety and depression may effect on mental health. Having Knowledge on healthy behavior or good behavior may help to guide the children to become a good person.

However, the study has many limitations. It is a descriptive study done in small size sample. The same study with larger samples. Messages and teaching students to reflect and control their own behaviors, which would be useful to teach as part of a wider social and emotional aspects of learning curriculum.

\section{Recommendations}

1. 1.A study can be carried out to evaluate the effectiveness of various teaching strategies like selfinstructional module, booklets and computers assisted instructions on promoting healthy behavior in school children

2. Arrange training programmes for teachers to various special schools

3. A similar study can be conducted with the experimental research design

\section{Acknowledgement}

The author is grateful to the authorities of Primary schools, Almasguda, Hyderabad, Telangana

\section{Ethics}

Ethical clearance obtained before conducting study. It is confirmed that there won't be will be any ethical issues after the publication of this manuscript.

\section{References}

Achenbach, T. M., Becker, A., Döpfner, M., Heiervang, E., Roessner, V., Steinhausen, H. C., \& Rothenberger, A. (2008). Multicultural assessment of child and adolescent psychopathology with ASEBA and SDQ instruments: Research findings, applications, and future directions. Journal of Child Psychology and Psychiatry, 49(3), 251-275. https://acamh.onlinelibrary.wiley.com/doi/abs/10.11 11/j.1469-7610.2007.01867.x

APA. (2013). Diagnostic and Statistical Manual of Mental Disorders, 5th edition. American Psychiatric Association. Arlington, VA., American Psychiatric Association, 2013. 
Bhatia, M. S., Bhasin, S. K., Choudhary, S., \& Sidana, A. (2000). Behaviour disorders among children attending a nursery school. J Ment Health Hum Behav, 5, 7-11.

Dutta, P. (2014). "Pediatric Nursing " 2 nd edition,2014, Published by Jaypee Publishers, Page no.186-190.

Malhotra, S., \& Patra, B. N. (2014). Prevalence of child and adolescent psychiatric disorders in India: A systematic review and meta-analysis. Child and adolescent psychiatry and mental health, 8(1), 1-9. https://link.springer.com/article/10.1186/1753-2000$8-22$

Rajanidevi, S., (2019). A Study to Assess the Knowledge of Primary School Teachers Regarding Behavioral Problems and their Prevention among School Going Children in Selected Government Primary Schools at Bagalkot with a View to Develop an Information Booklet. International Journal of Innovative Science and Research Technology ISSN No, 2456-2165.
Sagar, R., Dandona, R., Gururaj, G., Dhaliwal, R. S., Singh, A., Ferrari, A., ... \& Dandona, L. (2020). The burden of mental disorders across the states of India: The Global Burden of Disease Study 1990-2017. The Lancet Psychiatry, 7(2), 148-161. doi.org/10.1016/S2215-0366(19)30475-4

Sunitha, S., \& Gururaj, G. (2014). Health behaviours \& problems among young people in India: Cause for concern \& call for action. The Indian journal of medical research, 140(2), 185.

https://www.ncbi.nlm.nih.gov/pmc/articles/PMC4 216492/

Vijayan, P., Chakravarthi, S., \& Philips, J. A. (2016). The role of teachers' behaviour and strategies in managing a classroom environment. International Journal of Social Science and Humanity, 6(3), 208. http://www.ijssh.org/vol6/644-H006.pdf

\section{Abbreviations and Units}

BED: Bachelor of Education 